\title{
Challenges Faced by Pupils with Disabilities in Accessing Primary Education in two Selected Inclusive Education Piloting Schools in Livingstone District
}

\author{
Benson Zemba \& Ferdinand M. Chipindi \\ University of Zambia
}

\begin{abstract}
The study aimed to examine the challenges faced by pupils with disabilities in accessing primary education at two selected inclusive education piloting primary schools in Livingstone district of Southern Province. The researchers adopted a descriptive case study approach with a qualitative perspective. Data were analysed using the thematic approach. The study found that the views of most school stakeholders were predominantly positive, reflecting an acceptance of the inclusive status of the schools. The absence of significant negative attitudinal barriers, improvements in school accessibility, progress in teacher training and the production of locally made Inclusive Education (IE) modules are noticeable areas of achievement. The study concludes that despite the presence of various exclusionary factors, the two schools have made some observable headway towards the improvement of inclusive learning for children with disabilities. The study puts forward various recommendations for IE implementation and future research in Zambia.
\end{abstract}

Keywords: challenges, disabilities, inclusion, exclusion, demandside, supply-side

\section{INTRODUCTION}

$\mathrm{B}$ etween 93 million and 150 million children are estimated to live with disabilities (United Nations Scientific and Cultural Organization [UNESCO], 2015). Currently, there is no accurate or precise figure on children with disabilities, as there is a lack of country-level data on disability prevalence. The right to education for persons with disabilities is recognised in Article 24 of the United Nations Convention on the Rights of Persons with Disabilities (CRPD) (United Nations, 2006) and in Goal 4.5 of theUN's Sustainable Development Goals, which ensures inclusive and equitable quality education and promotes life-long learning opportunities for all, including persons with disabilities(United Nations [UN], 2019). For many countries globally, the CRPD is the primary resource for adopting inclusive education (IE) for children with disabilities (CWDs). Zambia first ratified the CRPD in 2008, and the country has included persons with disabilities in various policies and laws ever since the amended constitution of 1996 (the Republic of Zambia, 1996a). There are currently several laws and procedures that cover persons with disabilities, including some specifically within the education sector, such as Educating Our Future policy (Ministry of Education, 1996). The Persons with Disabilities Act (the Republic of Zambia, 2012) provides for free primary education for persons with disabilities. It also ensures that persons with disabilities are not excluded from accessing secondary and higher education in the communities in which they live. The Act also sanctions physical access to educational institutions. It ensures individualised support and access to alternative forms of communication and allowances to cover extra costs attributed to learning (the Republic of Zambia, 2018).

There is a growing commitment to include disability in the education sector planning. Zambia is beginning to implement a range of evidence-based policies and programs, collecting disability data, and identifying the key barriers that might hinder or prevent children with disabilities from accessing, participating, or learning in school (GPE, 2018). Zambia has had exciting experiences on how to make schools inclusive, including initiatives at the grassroots level. For example, the Inclusive Schooling Programme (INSPRO) was piloted in the Kalulushi district on the Copperbelt Province in 1997 and later scaled up to twenty-one districts with bilateral and multilateral development agencies, and other stakeholders (Chilufya, 2005). The INSPRO aimed to improve the quality of primary, secondary, and tertiary education for learners with disabilities, increase their access to education, and develop an assessment protocol for early identification of special educational needs (UNESCO, 2016).In addition to INSPRO, other programmes promoting inclusive education in Zambia have been implemented by organisations such as Sight Savers Zambia, Child Fund, Leonard Cheshire, and the DEAR Project. Thus, reaching children with disabilities is an essential priority of the Ministry of General Education. Still, this effort has been influenced or thwarted by various demand-side and supply-side barriers at national, provincial, district and school level. Despite sizeable advances in these realms, challenges in inclusive education remain unresolved. The CBR(community-based rehabilitation, Zambia support programme) notes indicate that there are many different barriers or challenges to teaching CWDs that work as 
disablers to inclusion. These barriers are often reflected in national policies and strategies; education sector plans (ESPs); robustness of disability prevalence data; socio-cultural perception of disability; school accessibility; availability of teaching materials; teacher preparedness; curriculum provisions; learning outcomes and multi-sectoral approaches to disability inclusion. These barriers can affect CWDs in a multifaceted way both at the community and school level.

\subsection{Statement of the Problem}

Much attention has been given to what inclusive education is all about without giving specific experiences and examples of challenges in its implementation at school and national level. Several research gaps have been identified that may be linked to the implementation of inclusive education in Zambia and the world. Some of the challenges faced in inclusive education, such as the achievement gap between non-disabled students and disabled students(Male \& Wodon, 2017), the gap between research and practice (Schneider \& McDonald, 2007), and inequities in educational opportunities for people with disabilities(Malungo, Nabuzoka, Paul, \& Sachingongu, 2018), can be attributed to the dearth offocused researchstudies on inclusive education in Zambia.

\subsection{Objectives}

The study's overall objective was to investigate the barriers faced by pupils with disability in accessing primary education at two selected schools in Livingstone district of Southern province of Zambia. The specific objectives were:

i. To evaluate how school personnel, non-disabled pupils, community-based rehabilitation officials and parents view the inclusion of pupils with disabilities at the two selected schools in Livingstone district.

ii. To uncover the challenges pupils with a disability face at two selected schools in Livingstone district of Southern province of Zambia.

iii. To evaluate the quality of inclusive education practices at the two selected schools.

iv. To profile the type of support that the government and cooperating partners render to the two selected schools.

\subsection{Significance of the Study}

As Zambia intensifies its efforts to implement IE in schools and across the world, this study might provide additional light on the challenges faced by CWDs. It is further hoped that the information obtained from this study might be of use to policymakers and other key stakeholders in formulating policies and interventions that would ensure full implementation of inclusive education, particularly in primary schools. The study findings might enhance awareness by regular teachers and school managers to rigorously address implementation challenges at the school level.

\subsection{Theoretical Framework}

Kombo and Tromp (2009)define a theoretical framework as a collection of interrelated ideas based on theories. Disability can better be understood by using several theoretical models drawn from different disciplines of social sciences. This study was guided by Cunningham and Fleming's social inclusion theoretical model (2009). The social inclusion model, as proposed, is an amalgam of social inclusion and social exclusion concepts.

The idea of social exclusion originated in France in the 1970s with ReneLenoir's Les Exclus: Un Francais Sur Dix in 1974(Peters \& Besley, 2014). Lenoirwrote about specific groups of people who he referred to as the mentally and the physically disabled, suicidal people, elderly invalids, abused children, drug addicts, delinquents, single parents, multiproblem households, marginal, asocial persons, and other"social misfits(United Nations, 2016). Although there is no universally agreed benchmark for exclusion, lack of participation in society is at the heart of nearly all definitions put forth by scholars, government bodies, non-governmental organisations and others. Overall, exclusion describes a state in which individuals with disabilities are unable to participate fully in economic, social, political and cultural life and the process leading to and sustaining such a state. According to the social exclusion model, people with disabilities are often present but not partof the community(Ngulube, 2016). In this research exclusion mostly refers to when children with disabilities are not permitted to register to attend a school or register but are told not to come to school or when there are conditions placed on their attendance (UNICEF, 2013).

The social inclusion model has arisen from concerns over social exclusion. For the present research, social inclusion is defined as improving the terms of participation in society for people who are disadvantaged based ondisability(United Nations, 2016). Thus, inclusion is both a process and a goal. Promoting inclusion requires tackling social by removing barriers to disabled people's participation in society and taking active inclusionary steps to facilitate such participation.

The rationale for selecting the social inclusion model rests in the assumption that accessto and participation in education for learners with disabilities can be improved if exclusionary mechanisms are identified and removed. This requires both addressing the drivers of exclusion, including educational policies and educational institutions as well as discriminatory attitudes and behaviours, and actively"bringing disabled people i" "(United Nations, 2016). The nature of education policies and practices in educational settingscurrently define the nature of education forlearners with disabilities, thus drivingeducational exclusion(Peters \& Besley, 2014).

The low enrollment and school completion levels show that educational institutions may be systematically denying pupils with disabilities the recognition that would enable them to participate fully in education and society. Discriminatory 
attitudes and behaviours towards the person with disabilities further drive exclusion.

\section{LITERATURE REVIEW}

The United Nations Educational Scientific Cultural Organization (UNESCO) defines inclusive education asa process of addressing and responding to the various ranges of needs of all learners through increasing participation in learning, cultures and communities, and reducing exclusion within and from education. It involves changes and modifications in content, approaches, structures and strategies, with a shared vision that covers all children of the appropriate age range and a conviction that it is the state's responsibility to educate all children (UNESCO, 2005).

The Salamanca Statement (1994) was the first to test at a global level the historically held idea that children with disabilities do not belong in mainstream schools or general education systems. This led to the introduction of a rightsbased approach to the education of children with special education needs and disabilities(Florian, 2019). This is reflected inthe following widely quoted clause of the Salamanca Statement:

regular schools... are the most effective means of combating discriminatory attitudes, creating welcoming communities, building an inclusive society and achieving education for all; moreover, they provide effective education to the majority of children and improve the efficiency and ultimately the costeffectiveness of the entire education system" (Statement ix).

This statement further widened the concept of inclusive education, connecting it to the Education for All movement and the school improvement and effectiveness agenda. The idea of inclusive education has further been drawn even more comprehensive to include all marginalised and vulnerable populations. This has resulted in it underpinningtoday's international evaluations of the disparities in educational systems - not only in terms of who has access to them but also in terms of the quality of education provision (Florian 2019).

The Incheon Declaration agreed at the 2015World Education Forum, emphasises that that to achieve the full scope of human development visualised in the SDGs 2030, all forms of discrimination, exclusion, disparities and inequalities in access, participation and achievementagainst youth and children with disabilities should be dealt with, irrespective of the severity or nature of their disabilities(UNESCO, 2015). This statement and the follow upundertaking made in the Brussels Declaration that followed the 2018 Global Education Meeting embraced the idea of disability inclusion in education by defining it as the right to safe, quality education and learning throughout(UNESCO, 2018).

Barriers to learning refer to any internal or external factors to the learner, that cause a hindrance to thatperson's ability to benefit from schooling (Zwane and Malale, 2018). Children with disabilities worldwide face cultural, economic and social barriers from within and outside the education system that directly or indirectly impact their ability to get a high-quality education (World Bank, 2018). Demand-side barriers could manifest as stigma and attitudinal barriers - alternatively, as internalised parental and family misconceptions aboutchildren's ability to learn. Family resources and caregiving dynamics and financial supports could also be visible results of the barriers. Welfare provisions and placement eligibility criteria could also be manifestations of the demand-side barriers. Supply-side barriers refer to the physical accessibility of school buildings, such as classrooms and toilets and their community. Transportation means to get to school; inaccessible learning materials, inflexible curricula, teaching methods and examinations; teacher and educator knowledge on inclusive teaching practices and discrimination based on disability (World Bank, 2018). Parents' attitude toward disability is the most critical factor in determining whether a child attends school or not. The shame of having a child with a disability and the perception that such children cannot take care of themselves can keep the child hidden at home (Jelagat \& Ondigi, 2017). Persons with disabilities are often not valued by society. They are considered objects of charity as their potential and abilities are not recognised. Children with disabilities are always often seen as incapable and economically unproductive and needing to be cared for (GPE, 2018).

In Ghana, the most critical barriers to free universal education for students with disabilities are negative attitude and prejudice. Several Ghanaians still attribute the causes of disabilities to curses from gods (Agbenyega, Deppler, \& Harvey, 2005). For example, the people of Northern Ghana believe that a newly born child who is disabled is not a human being. Mariga et al. (2014) underline that stigma and shame associated with a disability persists in many cultures, communities and countries. In parts of SSA, CWDs are regarded as shame objects that should be kept at home, hidden from those outside the family (Adeniyi \& Omigbodun, 2016).

Muwana and Ostrosky (2014) examined Zambian pre-service teachers' attitudes toward the inclusion of students with disabilities in general education classrooms. Results indicated that teachers had positive attitudes toward including learners with disabilities in general education classrooms. Besides, most pre-service teachers who took part in the research observed that learners with special needs have a fundamental right to be educated in the general education classroom. that inclusion promotes self-esteem among students with special needs. This perspective is in line with the CRPD document's views (United Nations, 2006).

In schools where CWDs are enrolled in mainstream schools, prior assumptions about their capabilities may negatively affect their experiences. For example, at a mainstream primary school in South Africa, Ngcobo and Muthukrishna(2011) found that students were divided into three groups: green, orange and red, according to their perceived abilities. CWD was automatically allocated to the 
red group, based on the assumption that they were the least able.

The lack of robust data on disability is most commonly cited as a critical issue regarding children with disabilities. In the GPE report, thirteen countries including Afghanistan, Benin, Burkina Faso, Cameroon, Comoros, The Gambia, Guyana, Haiti, Mozambique, Pakistan, Sierra Leone, Somalia, Tajikistan, Uzbekistan, and Vietnam lacked disability prevalent data (GPE, 2018). Data insufficiency on the number of CWDs presents a challenge to determining their needs and barriers to participation. Also, it prevents estimating the type and kind of support they need to ensure full participation and learning. Planning for children with disabilities can be extremely challenging when information is so limited (Mariga, McConkey, \& Myezwa, 2014).

Various researchers point out that data from some countries may not accurately reflect persons with disabilities concerning education. De and Singal (2016) highlight the difficulties with official figures of enrolment of children with disabilities in education in India. According to De and Singal, many children with disabilities may be invisible both in the classroom and community, with teachers unaware of, or unable to identify, individuals with disabilities in their classes.

Similarly, DFID and UKAID (2010) describe the underreporting of the disability worldwide. In some cases, this under-reporting is due to the stigma of having a child with a disability. Many national household studies in the developing world massively underestimate the number of CWDs, partly because many children born with disabilities are not registered due to weak child registration systems. Estimates of the percentage of children with disabilities in school are incorrect, underestimated CWD identified. Disability-disaggregated data is also not available in several countries, making it impossible to track children with disabilities' learning outcomes.

\section{Social Inclusion versus Social Exclusion}

Although there is no universally agreed definition for social exclusion, lack of participation in society is at the heart of nearly all definitions of scholars, government bodies, nongovernmental organisations and others(Levitas, Pantazis, Fahmy, Gordon, Lloyd, \& Patsios, 2007). Overall, social exclusion describes a state in which individuals are unable to participate fully in economic, social, political and cultural life and the process leading to and sustaining such a state(United Nations, 2016). It is a complex and multi-dimensional process that involves the lack of denial of resources, rights, goods and services, and the inability to participate in the healthy relationships and activities, available to the majority of people in a society, whether in economic, social, cultural or political arenas. It affects both the quality of life of individuals and the community's equity and cohesion as a whole(Levitas et al., 2007).

Social inclusion is defined as the process of improving the terms of participation in society for people who are disadvantaged based on age, sex, disability, race, ethnicity, origin, religion, or economic or another status, through enhanced opportunities, access to resources, voice and respect for rights(United Nations, 2016). Thus, social inclusion is both a process and a goal. In the present report, it is argued that promoting social inclusion for learners with disabilities requires tackling social exclusion by removing barriers to children with disabilities participation in society and taking active inclusionary steps to facilitate such participation.

The degree of inclusion or exclusion for different disability groups may vary across time and across other areas, dimensions and elements(Ainscow, Alan Dyson, \& Weiner, 2013). Areas of inclusion refer to different spaces in which learners interact through interpersonal relationships, such as classrooms, schools, or community centres. Young people and children with disabilities can be included or excluded along different dimensions: physical; social; psychological; or systematic(UNESCO, 2018).In reviewing the range of educational provision across various countries, it becomes clear thatmany are at different stages of development on the trajectory from exclusion, through segregation and integration, conclusion.

In this section, we attempted to review relevant literature on barriers to the implementation of inclusive education policy in general. Very little attention has been paid to barriers to effectiveness in inclusive education in primary schools practising inclusive education in most studies done in Zambia. With the help of community-based rehabilitation (CBR) in the implementation of ideal IE, we see the practical way of implementing inclusive education in the two inclusive piloting schools in Livingstone. This is the gap that this study sought to address. The next section discusses the methodology used in the study.

\section{METHODOLOGY}

\subsection{Research Design}

This study used a descriptive case study research design using a qualitative approach. According to both Stake (1995) and Yin (2003) descriptive case studies are based on a constructivist paradigm. Constructivists maintain that truth is relative and that it is dependent onone's perspective. This approach recognises the importance of the subjective human creation of meaning butdoesn't reject outright some idea of objectivity (Baxter \& Jack, 2008; Chipindi, 2009; and Thomas, Serenje-Chipindi \& Chipindi, 2020). In this study, a descriptive case study design was selected based on the rationale that the data collected would contain information about people's views, attitudes, and opinions about the challenges that learners face in an inclusive school.

\subsection{Study Population}

In this study, the population comprised school headteachers, regular classroom teachers, non-disabled learners, community-based rehabilitation officers and parents/caregivers of learners with disabilities in primary 
schools in Livingstone. Creswell (2018) describes the population as a group of individuals from which samples are taken for measurement.

\subsection{Study Sample}

$\mathrm{Ng} \operatorname{andu}(2013$, p. 13)stated that a sample is referred to as"the number of participants selected from the universe to constitute a desired sample."This study's total sample was 30 and consisted of 2 Head Teachers, six regular classroom teachers, 2 CRB officials, four parent-teacher committee members, and 16 non-disabled learners. All the participants had connections with interacted with learners with disabilities at the two selected school.

\subsection{Data Collection Instruments}

Data collection refers to gathering information to answer research questions in the research (Daka, Chipindi and Mwale-Mkandawire, 2020; Chipindi and Chipindi, 2016). The instruments used for data collection were an interview guide and a focus group guide.

\subsection{The Interview Guides}

In-depth interviewing is a qualitative research technique that involves conducting intensive individual interviews with a small number of research participants to explore their perspectives on a particular idea or situation (Boyce \& Neale, 2006; Chipindi and Doyle, 2017; Chipindi, 2018). The study used four separate, but related interview guides for headteachers, teachers, CBR officials and PTA members.

\subsection{Focus Group Discussion}

The study utilised two eight-member focus groups, one for each participating school. We included teachers; learners, members of the community. The researchers took notes, and the conversations took approximately one hour. The focus group guide was intended to elicit views and opinions from the non-disabled students about the perceptions and attitudes about learning with students with disabilities.

\subsection{Ethical Considerations}

The research followed ethical standards and guidelines set out by the University of Zambia and Zimbabwe Open University. Permission was sought from the Ministry of General Education in Southern Province, which facilitated access to the two selected research sites. Before each interview or focus group discussions, every participant was informed of the study's purpose, and informed consent was obtained. Direct permission was obtained from participants above the legal age (18 years), while guardians/caregivers provided consent for non-disabled pupils below 18 years of age. Participation in this research was purely voluntary, and respondents could decline to answer any question during the interview.

\section{FINDINGS}

\subsection{Head Teachers' Views on the Inclusion of Pupils with Disabilities}

The two headteachers who took part in the study held inherently similar views about pupils' inclusion in the mainstream classrooms. A perspective that quickly emerged was how they viewed inclusion as school administrators; one headteacher had this to say:

\begin{abstract}
We have a mission to make sure our school accept all learners, including those with disabilities. The new policy on inclusive education is apparentin this. But we can only do this through our means. Learners with different abilities can co-exist which $l$ never thought before $l$ was transferred to head this school. As a person in charge of the school, my work is to make sure that all pupils learn together, play together, and eat together. We are a family. (Headteacher 1)
\end{abstract}

The point above illustrates a significant tenet of inclusive education. Inclusive education is only not only about students with disabilities but for all pupils in the school setup. The role played by in-service training workshops on IE inclusive education can be seen in the comment below.

Teachers in this school have been to various workshops to learn about inclusive education. We understand what inclusive education is about and our experiences in the last few years will help us with the goal of teaching learners with disabilities. We have a learnt lot about this conceptabout how we can include children with disabilities in our general classrooms and all other school activities. The teachers do not look only look at academic performance but go beyond what other tasks children with disability can do. All CWDs are accepted as they are without preconceptions. Teachers try toinclude all learners in learning during regular classroom lessons (Headteacher 2).

The overall theme that emerges from the two headteachers" views is that of acceptance of IE in theirschools' mission statements and an understanding of the CBR programme goals for children with disabilities. The school administrators recognise the importance of strategic school leadership in IE implementation, the undertaking of teacher development programmes and the role these might play in teacher motivation and attitude change among all school stakeholders.

\subsection{Teachers' Views on the Inclusion of Pupils with Disabilities}

We also collected teachers' views about inclusion in face-toface interview guides. Similar to the perceptions of 
headteachers, class teachers showed related views. In this study, the teachers regard the inclusion of learners with disabilities in their mainstream classrooms as their right. These views corroborate the sentiments of the headteachers. For instance, one respondent said: "All learners are different, whether disabled or not. We must respect their rights. While we learn about individual differences during teacher training, the CBR shortcourses have taught us more to respect these differences(Inclusive teacher 6).

Another sub-theme that emerged from the teachers' viewpoints was the acceptance of inclusiveness. A teacher reported that "all children were accessing, participating, achieving in their own right" reflecting an acceptance of inclusive education. Thus, teachers understand that IE is about all pupils -those with and without disabilities-learning together. It also seems the motivation to teach learners with disabilities was remarkably high. As one teacher put it:"We try our level best to teach all students together in the same classroom at the same time and by all means possible following the same curriculum while differentiating for the learner with disabilities. This, at times, can be very demanding"(Inclusive teacher 3).

One teacher alluded to the benefits that learners with intellectual disabilities accrue in an inclusive context.

We have several learners with intellectual disabilities in our school. They enjoy learning with their friends. They [learners with an intellectual disability] enjoy being supported by their peers, and our nondisabled pupils love to help them with academic work as well as extracurricular work(Inclusive teacher 2).

The view of this study is that teachers' interpretations of disability inclusion are an outcome of the dynamic interaction with contextual issues that determine how inclusion has been enacted at the two schools and how they teach and support learners. These factors include initial teachers training, teacher motivation and direct exposure to inclusive education pedagogy in in-service courses.

\subsection{CBR Officials' Views on the Inclusion of Pupils with Disabilities}

The two Community Based Rehabilitation officials who took part in the study further highlighted the importance of inservice training in IE pedagogy and the need for communitysensitisation on disability inclusion. For instance, one CBR official had this to say: "CBR officials, teachers and community assistants go into the communities tosensitise people about the importance of all children learning together under one roof or in the same school instead of being placed in special schools"(CBR Official 2).

Another CBR official commented on the effects of in-service courses that teachers had been receiving.
It seems our investment in CPD [Continuous professional development] in inclusive education has paid off. All teachers in the two schools have been trained in IE pedagogy. Their [teachers] knowledge in IE has improved, and their classroom practices keep getting better. We have seen an improvement in attitudes towards children with disabilities as well(CBR Official 2).

Another CBR official reported that children with disabilities in regular classes enjoy certain benefits than comparable students in non-inclusive settings. Some of these benefits include social advantages (playing with others, lack of isolation), involvement in extracurricular activities, and removal of social prejudice for people with disabilities.

Inclusiveeducation is allowing all children to
be together. From the time this project
started, we have found out that CWDs are now
included in social activities at school
and community level. Our trained community
workers ensure that CWDs are identified and
place in schools and not excluded as in the
past. We also work with other strategic
partners such as disability organisations,
health workers and others who share our IE
objectives(CBR1).

The two officials' views signify the critical role CBR programme has played in the implementation of IE at the pilot schools. It seems IE is better implemented when teachers are given more skills in teaching CWDs when linkages are created with the surrounding communities. Other cooperating partners in the locality are seen as equal stakeholders.

\subsection{Parent-Teacher Association Members' Views on the Inclusion of CWDs}

Like the school staff and CBR officials, the four PTA members generally agreed with the concept of IE reflecting the impact of communitysensitisation programmes enacted through the CBR project. "At first, we didn't understand what they meant that children with disabilities could learn at the same schools as those without disabilities. Many people thought it wasstrange. But the more they explained to us, the clearer it became(PTA member).

PTA members also mentioned that CWD should have the fundamental right to education, along with other children. One parent had this to say:

Our children who have difficulties are just like other children, though different in some ways. But they also need to go to school. We need more trained teachers in our schools for these children. They have to be prepared so that they can also teach children who have disabilities. 
PTA members also raised the issue that learners with disabilities should, by all means, possible, attend the school closer to their homes. One respondent stated that "We need more schools that accept CWDs in our communities. Some children travel long distances just to get to school. This can be tiring. This discourages both children and parents and children and can be costly"(PTA member). The views aired by PTA members on IE programme implementation indicated that an inclusive programme was beneficial for children with disabilities as compared to separate special education units. The need to have more IE schools in the local communities shows that school accessibility can be an issue.

\subsection{Non-Disabled Pupils' Views on the Inclusion of Pupils with Disabilities}

Sixteen non-disabled pupils also expressed their views in two focus group discussions about learning together with children with disabilities. It should be noted that the FGDs were conducted in Tonga, the language that most learners speak at the two research sites. The pupils had diverse opinions of what it meant to be an "inclusive school," a term used frequently during FGDs; and how they perceived their learning experiences together with CWDs. While these perspectives varied in some ways, there were significant commonalities. Some themes were widespread across the two focus groups between the two primary schools, although minimal differences in CWD attitudes emerged. Two main themes emerged from the analysisof learners' perspectives: (a) school sense of belonging, (b) inclusion.

\subsection{Challenges to Inclusive Education}

In this study, several challenges of accessing inclusive education emerged, and they are discussed below.

\subsubsection{Availability of Teachersand Teaching Capacity}

Several studies consistently show that teachers' availability and their capacity to teach CWDs is a significant exclusionary barrier to implementing inclusive education. The findings of this study were no exception. Despite continuous professional development activities that are infused into the CBR programme, teacher capacity remains a need for concern. Headteachers in both schools reported the need for more trained teachers to support CWDs. They also shared a need for multi-disciplinary work teams to help identify, assess, and place CWDs.

We don't have enough teachers to support learners with disabilities. But we need more [teachers] so that every child [with a disability] is reasonably supported. At the moment, our teachers are a bit overstretched in terms of teaching workload. Our school requires a multi-disciplinary team. We need more trained in IE with a background in disability screening and assessment. Such a team is needed in this school (Headteacher, 2).

Teachers' capacity and experience to teach CWDs also emerged as an essential exclusionary sub-theme towards special education. It seemed that recently appointed teachers at the two schools lacked the necessary knowledge and did not have enough practical expertise working in inclusive setups. For instance;

Our hard of hearing learners have challenges in communication with teachers in a classroom situation because most teachers do not have sign language skills. They learn sign language from the learners themselves. For some teachers, teaching in inclusive school is a new experience. They need guidance and support because they have never done it before (Headteacher 2).

\subsubsection{The Curriculum}

Various perspectives were offered on the curriculum for learners with disabilities that the two schools were following. All teachers reported that they wereutilising the mainstream curriculum together with locally produced modules. The teacher described how they always had to adapt and modify the curriculum to suit CWDs. "We continuously have to use our professional judgement and experience to make the adjustments to the mainstream curriculum content, way of teaching and how we assess learning outcomes in terms of achievement"(Inclusive teacher 1).

One teacher reported that the academic performance of CWDs was way below expected level if comparisons were to be made with their disabled peers while following the mainstream curriculum. Another teacher mentioned difficulties in assessing and grading of work presented by children with disabilities.

We don't know how to assess all the different work types that children withdisabilities give us to mark or grade. We have been told in various training workshops to use formative assessments, but they are clear guidelines and instructions from the Ministry [of Education] on how to do this. So we rely mainly on our initiatives and the modules that the CBR has given us (Inclusive teacher 4).

\subsubsection{School Accessibility}

Despite being known as a significant barrier to inclusive schooling in most educational setups, only selected school infrastructure aspects were acknowledged as barriers in the two schools. This perhaps comes out as a success story of the inclusive education pilot programme. An observation of the school surroundings during the data collection process showed carefully constructed pathways, ramps and doorways. Nevertheless, the following was pointed out:

Livingstone town is very sandy. It has a lot of sand in most areas, and for learners using wheelchairs, they will have a real challenge with mobility significantly when they are dropped 
off at the school gate, and there is no one to assist them in pushing the wheelchair in the sandy soil. The sandy soil is a significant hindrance in moving the wheelchair up to the concrete corridors and pathways (Inclusive teacher 4).

Additionally, teachers described some school areas, such as classrooms and playgrounds as not being disability-friendly.

Some of the rooms in the school are not suitable for learners with hearing disabilities. The rooms are acoustically low for the deaf and hard of hearing pupils. We have adequate ventilation. Still, the lighting in some rooms is not sufficient, especially for learners with low vision. Learners with physical impairments like cerebral palsy cannot fully take part inextracurricular activities because our playing grounds were not designed with them inmind(Inclusive teacher 4)

Teachers reported difficulties with learner movement to and from school. One teacher reported that "traffic sometimes is not friendly and pose a danger to CWDs".Inclusive Teacher 5 similarly said that: "In some cases, local mini-buses and taxis drivers refuse to carry CWDs because they fear to contravene traffic rules, as their vehicles are not designed to carry wheelchairs and clutches.

Despite notable improvements in school physical infrastructure development during the CBR pilot programme, barriers remain for various disability types. According to the two headteachers, this was evident for children with severe disabilities who are not even enrolled in the schools. For example, one headteacher said: "While we can register children with mild to moderate intellectual disabilities into our school, wecan't take in those [children] who have severe intellectual and physical disabilities because our school does not have the infrastructure for them(Headteacher 1).

These findings show that despite scoring some success in school accessibility, specific barriers remain a challenge in implementing inclusive education, even in schools carefully chosen for the pilot programme.

\section{DISCUSSION}

\subsection{How School Stakeholders View the Inclusion of Learners with Disabilities}

In this study, the stakeholders refer to headteachers, teachers, non-disabled pupils, CBR officials and PTA members. The general finding of this study indicates a widespread acceptance of inclusion by all stakeholders. The positive views that emerged suggest that CWDs are accepted and seen as part and parcel of the school community in this inclusive pilot CBR programmes. This acceptance of IE can be explained from various perspectives.

\subsubsection{Clarity of Purpose for Inclusive Education Implementation}

The stakeholders' positive perspectives at the school level can be explained in part by the greater clarity of purpose and understanding about what it means to become an inclusive school (Miles \& Ainscow, 2011). The feelings of belongingness among learners, the motivation levels among school personnel, inferred from their responses and the support of parents and CBR officials all point to the notion of clarity of purpose in implementing an active, inclusive education setup.

This implies an understanding of the vision and mission of an IE philosophy. According to Fugazzotto(2009), mission statements dictating the organisation's nuclear activities, including schools. For IE schools, mission statements are imperative, as they can assert which parts of the institution should be points of emphasis, how resources are allocated towards the education of CWDs. School administrators, teachers, pupils, PTA members and CBR officials who highly aware of the school mission of increasing the participation of learners with disabilities in all school activities, and reducing exclusion from the curricula, cultures and communities of the two schools are more likely to articulate well the purposes of IE and respond to the needs of CWDs. Restructuring the school cultures, school policies, and practices to respond to the needs of all learners and CWDs requires a great understanding of what an inclusive school should be, founded on evidence-based approaches to IE. In this study, stakeholder perspectives reflect the notion that inclusion is an ongoing active process. An inclusive school is on the move, constantly changing in line with the IE philosophy and mission, teacher and learner mindsets, approaches to teaching and learning and attitudes has reached a perfect state (Ainscow, Dyson, \& Weiner, 2013).

\subsection{Availability of Teachers and Teaching Capacity}

Studies consistently show that teachers' availability and the ability to teach is a significant exclusionary barrier to implementing IE for CWDs. Despite continuous professional development activities built into the CBR programme in the two pilot schools, this study revealed that teacher availability and capacity are still a concern. The call for more IE teachers who are well versed in inclusive pedagogy is possibly a reflection of the enhanced awareness by the local communities of the need for more school personnel due to children with disabilities identified and enrolled at the project schools.

One participant's view highlighted the need for an inclusive education team with special education teachers on board. There seems to be a reasonable recognition among IE experts that achieving inclusion will not be achieved by merely transplanting previous special education thinking and practices into mainstream contexts (Ainscow, Dyson, \& Weiner, 2013). Teachers' use of local core teaching modules for teachers in the CBR pilot programme ascribes to this view. This is additionally observed in the continuous professional development of teacher capacity in IE pedagogy workshops.

Thus, there is a need to move to a perspective that seeks toactualise learning by engaging with the whole class and school using locally produced teaching and learning materials 
and thus responding to diversity (Florian, 2019). As Bartolome (1994) explains, teaching methods are neither devised nor implemented in a vacuum. The use of particular teaching approaches and strategies arise from perceptions about learning and learners. In this respect, she argues, even the most pedagogically advanced methods are likely to be ineffective in the hands of those who directly or indirectly subscribe to a belief system that regards some students, at best, as disadvantaged and in need of fixing, or worse, as deficient and therefore, beyond fixing (Ainscow, Alan Dyson, \& Weiner, 2013).

However, this research's findings do not speak much to the concept of differentiation for learners with disabilities. A study by Florian and Black-Hawkins (Florian \& BlackHawkins, 2010) suggests that differentiation in a classroom for example, through some students being expected to complete simpler or less work - leads to learners seeing other students as different. Florian and Black-Hawkins (2010) suggest what they see as a more inclusive approach, where teachers create options for students to choose "how, where, when and with whom they learn", in conditions that are designed to respond to their individual needs

\subsection{Curriculum Flexibility}

Views around the curriculum centred on adaptability and modification as well the measurement of pupil progress. Teachers resort to their professional judgement to adapt and modify the general education curriculum, not surprising. Despite the development of local inclusive education modules to support the implementation of the broad education curriculum at the two research sites, teachers must continuously try to modify and adapt the learning processes to suit individual learners with various disabilities. Critical to this is that teachers may not fully understand the fundamental concepts necessary for curriculum adaptations and modifications for CWDs (Muzata, 2017).

Additionally, the highly centralised nature of the Zambian general education curriculum lends to its inflexibility. The curriculum is characterised by a lack of teacher and schoollevel autonomy, which act as barriers to local, needs-based adaptation. Rafael Mitchell(2017)refers to this as "one size fits curriculum, which is oftensummarised in a single textbook per subject or grade.

\subsection{School Accessibility}

Despite being known as a significant barrier to inclusive schooling in most schools in Zambia, only selected aspects of were acknowledged as challenges to inclusion in the two schools in the study. The sandy terrain of Livingstone district appears to be a challenge for CWDs travelling from distant homes. In the study accessibility to specific sections of the schools was an issue because of non-compliance with universal design principles, and many physical elements were observed that make it difficult to access learning in classrooms with non-disabled peers. These findings show that school accessibility barriers remain a noticeable challenge in the implementation of inclusive education, even in schools carefully chosen for a pilot programme.

Engaging with schools, communities, and parents is needed to understand better the challenges and solutions for physical access (UNESCO and Leonard Cheshire, 2019). This includes the role of School PTAs and including pupils with disabilities in the SMCs or parents of pupils. Physical infrastructure requirements for introducing assistive technology have also become critical in recent years, focusing on the availability of connectivity and electricity in schools (Zambia National Educational Coalition [ZANEC], 2018). This remains a considerable challenge in resource-poor countries such as Zambia and remote areas and is often coupled with a lack of technical maintenance capacities.

\section{CONCLUSION}

Despite twenty years of implementing inclusive education in Zambia, children with disabilities are still at a disadvantage in school enrollment, educational attainment, and learning. Many never enrol in school or drop out prematurely. Their learning outcomes are also often learned less while in school because of their disabilities and the lack of inclusive education policies and programs. The advantages of inclusion and the disadvantages of exclusion of all children in education are well known. Inclusive education provides an opportunity of increased quality education for all through systematic changes in the way learning experience is planned, implemented, and evaluated. Excluding children with disabilities from educational harms economies and societies. Additionally, exclusion from education and the occupational opportunities that schooling provides for individuals often lead to poverty.

However, challenges in IE remain unresolved. CWDs face exclusionary barriers that can be described as either demandside or supply-side obstacles. These impediments to inclusive education are an outcome of prejudicial socio-cultural perceptions, national policies and strategies on inclusive education, financing, the robustness of disability prevalence data, school accessibility issues, availability of teaching materials, teacher preparedness, curriculum provisions and poor inter-ministerial coordination to disability inclusion.

The findings of this study show a general acceptance of IE for CWD. However, various disablers to IE implementation were documented despite intense efforts and input from the CBR programme. Several exclusionary barriers were highlighted. These included economic challenges or financial and difficulties with movements to and from school for CWDs. There was also a lack of teaching and learning materials. Teachers were seldom available. Also, there were also some pedagogical hurdles, coupled with curriculum inflexibility. An important finding worth pointing out is the negative attitudes towards CWDs observed in surrounding nearby non-inclusive schools during the referral process of CWDs to the two pilot schools. These barriers were seen to impact the quality of teaching and to learn at the two research sites. The study 
further showed that the CBR implementation process mainly depended on cooperating partners' support with minimal support from the government.

Based on this study's findings, we recommend changes at the system level areneeded in Zambia at the national, provincial, and school level to deliver better learning outcomes forall CWDs.Inclusive education programmes are successfulwhen the system changes to accommodate teachers' training, the preparation of appropriate learning environments in schools, the empowerment of parents, and theeducation of community members and related professionals support service systems. Policymakers need to be involved because the morethey understand, the more supportive theybecome when policymakers understanddifferent disabilities, their causes, theirrights and inclusiveness, inclusive policy problems are then better handled.

\section{REFERENCES}

[1] Adeniyi, Y. C., \& Omigbodun, O. O. (2016). Effect of a classroom-based intervention on the social skills of pupils with intellectual disability in Southwest Nigeria. Child and Adolescent Psychiatry and Mental Health, 10 (1), 1-29.

[2] Agbenyega, J., Deppler, J., \& Harvey, D. (2005). Attitudes towards inclusive education. In Africa Scale (ATIA): An instrument to measure teachers' attitudes towards inclusive education forstudents with disabilities. Journal of Research and Development in Education, 1-5.

[3] Ainscow, M., Dyson, A., \& Weiner, S. (2013). From exclusion to inclusion: ways of responding in schools to students with special educational needs. Manchester: University of Manchester Press.

[4] Ainscow, M., Slee, R., \& Best, M. (2019). The Salamanca statement: 25 years and on.International Journal of Inclusive Education, 23 (7-8), 671-676.

[5] Bartolome, L. (1994). 'Beyond the methods fetish: towards a humanising pedagogy. Harvard Education Review, 54 (2), 173194.

[6] Baxter, P., \& Jack, S. (2008). Qualitative case study methodology: Study design and implementation for novice researchers. The Qualitative Report, 13 (4), 544-559.

[7] Boyce, C., \& Neale, P. (2006). Conducting in-depth interviews: A guide for designing and conducting in-depth interviews for evaluation input. Watertown, MA: Pathfinder International.

[8] Chilufya, J. (2005). Parents' and teachers' attitudes towards inclusive education in selected basic schools of Kalulushi district of Zambia. (Unpublished Masters dissertation). University of Zambia, Lusaka.

[9] Chipindi, F. M. (2009). The quality-quantity trade-off: Implications of expanded enrolments at two of Zambia's public universities (Unpublished master's dissertation). University of Zambia, Lusaka.http://dspace.unza.zm/handle/123456789/348

[10] Chipindi, F.M. (2017). Neoliberal governmentality and the deepening of academic tribalism in the Zambian academy: A commentary. International Journal of Multi-Disciplinary Research. ISBN (online): 34717102.https://www.researchgate.net/publication/320979075_Neolib eral_governmentality_responsibilization_and_deepening_academi c_tribalism_in_the_Zambian_academy_a_commentary

[11] Chipindi, F.M. (2018). Negotiating professional identities in a liberalised Sub-Saharan economy: A case of university of Zambia faculty (unpublished $\mathrm{PhD}$ dissertation). University of Minnesota, Minneapolis.

[12] Chipindi, F.M. \& Doyle, H. (2017). Zambia scoping study. In H. Doyle, A.M. Barrett \& A. Reeves (Eds.), Improving the quality of teaching in secondary education: scoping studies for Zambia,
Malawi, Tanzania, Côte D'Ivoire and Senegal (pp. 4-32). Bristol: Bristol University.http://dspace.unza.zm/handle/123456789/6744

[13] Chipindi, F.M. \& Chipindi, S.J. (2016). Trade-off issues in teacher education at the university of Zambia: Growing student numbers and the quality of teacher education processes. International Journal of Teaching and Learning in Africa 3(1), 82-86. http://dspace.unza.zm/handle/123456789/6745 .

[14] Chipindi, F.M. \& Vavrus, F. (2018). The ontology of mention: Contexts, contests, and constructs of academic identity among university of Zambia faculty. FIRE: Forum for International Research in Education, 4, (3), 102-116. ISSN: 2326-3873.

[15] Cresswell, J., \& Plano Clark, V. (2011). Designing and conducting mixed method research; 2nd Edition. Thousand Oak, CA: Sage.

[16] Creswell, W., \& Cresswell, D. (2018). Qualitative, quantitative, and mixed methods approaches. Los Angeles: Sage.

[17] Cunningham, A., \& Flemming, V. (2009). Theories of disability: findings from an analysis of Analysis of Textbooks on Human Behavior and Social Environment. Journal of Human behavior in Social Environment, 19, 10-25.

[18] Daka, H., Chipindi, F.M. \& Mwale-Mkandawire, M. (2020). The relationship between assessment practices and students' academic performances. A case of undergraduate students at the medical school of the university of Zambia, 2008 - 2016. Zambian Journal of Educational Management, Administration and Leadership, 1, (1), 143-156. ISSN: 2706-7416 (Print). http://dspace.unza.zm/handle/123456789/6742

[19] De, A., \& Singal, N. (2016, August 2016). Blog: The paradox of disability and education in India. Retrieved April 14, 2020, from The Impact Initiative for International Dvelopment Research:https://www.theimpactinitiative.net/blog/blog-paradoxdisability-and-education-india

[20] DFID and UKAID. (2010). Guidance Note: Education for children with disabilities - improving access and quality.

[21] Florian, L. (2019). On the necessary co-existence of special and inclusive education. International Journal of Inclusive Education, 23 (7-8), 691-704.

[22] Florian, L.\& Black-Hawkins, K. (2010). Exploring inclusive pedagogy. British Educational Research Journal, 37 (5), 813-828.

[23] Fugazzotto, S. J. (2009). Mission statements, physical space, and strategy in higher education. Innovative Higher Education, 34 (5), 285-298.

[24] GPE. (2018). Disability and inclusive education: A stocktake of education sector plans and gpe funded grants. Washington D.C: Global Partnership for Education.

[25] Jelagat, K. J., \& Ondigi, S. (2017). Influence of socio-cultural factors on inclusive education among students \& teachers in Nairobi integrated educational programme, Kenya. IOSR Journal of Research and Method in Education, 7 (1), 49-55.

[26] Maasen, P. (1996). The concept of culture in higher education. Tertiary Education and Management, 153-159.

[27] Male, C., \& Wodon, Q. (2017). Disability gaps in educational attainment and literacy, the price of exclusion: Disability and education notes series. Washington, DC: The World Bank.

[28] Malungo, R., Nabuzoka, D., Paul, R., \& Sachingongu, N. (2018). Qualitative study from Zambia on barriers to facilitate lifelong learning. Lusaka: SINTEF Digital.

[29] Mariga, L., McConkey, R., \& Myezwa, H. (2014). Inclusive education in low income countries: Aresource book for teacher educators, parent trainers and community development workers.Cape Town: Atlas Alliance and Disability Innovations Africa.

[30] Miles, S., \& Ainscow, M. (2011). Responding to diversity in schools. London: Routledge.

[31] Ministry of Education. (1996). Educating our future: National policy on education. Lusaka: Republic of Zambia.

[32] MoGE. (2018). Early grade screening tool. Lusaka: Ministry of General Education.

[33] Muwana, F. C., \& Ostrosky, M. M. (2014). Factors related to preservice teachers' attitudes towards inclusion: A case for Zambia. International Journal of Inclusive Education, 18 (8), 763-782. 
[34] Muzata, K. (2017). Curriculum implementation for learners with special education needs: The case of selected inclusive and special schools in Zambia (Unpublished PhD Thesis).University of South Africa.

[35] Ng'andu, K. (2013). Writing a research proposal in educational research. Lusaka: UNZA Press.

[36] Ng'andu, K., \& Morberg, S. (2001). S. (2001). Moving towards inclusive schooling. Lusaka: BESSIP

[37] Ngcobo, J., \& Muthukrishna, N. (2011). The geographies of inclusion of students with disabilities in an ordinary school. South African Journal of Education, 31 (3), 357-368.

[38] Ngulube, J. (2016). Challenges and facilitators of inclusion policy implementation for special educational needs in post-primary regular schools in Zambia,(Unpublished master's dissertation).University of Dublin.

[39] Peters, M., \& Besley, T. (2014). Social exclusion/inclusion: Foucault's analytics of exclusion, the political ecology of social inclusion and the legitimation of inclusive education. Open Review of Educational Research, 1 (1), 99-115.

[40] Schneider, B., \& McDonald, S. K. (2007). Scale-up education: Issues in practice (Vol.2). New York, NY: Rowman and Littlefield

[41] Stake, R. (1995). The art of case study research. Thousand Oaks, CA: Sage.

[42] Thomas, M. A.M., Serenje-Chipindi, J \& Chipindi, F.M. (2020), Comparing course syllabi from A to Z: Examining the contexts, content, and concerns for social foundations of education in Australia and Zambia. In A. E. Mazawi \& M. Stack (Eds.). Course syllabi in faculties of education across the world: Bodies of knowledge and their discontents (pp 38-50). Sydney: Bloomsbury, ISBN 978-1-3500-9425-3 (hardback) 978-1-35009427-7 (online). http://dspace.unza.zm/handle/123456789/6619.

[43] UNESCO and Leonard Cheshire. (2019). Inclusive education for persons with disabilities - Are we making progress? Cali: UNESCO.

[44] UNESCO (2015). Education 2030: Incheon declaration and framework for action for the implementation of sustainable development goal 4: Ensure inclusive and equitable quality education and promote lifelong learning. Paris: UNESCO.

[45] UNESCO (2015). Education for all 2000-2015: Achevement and challenges efa global m nitoring report. Paris: UNESCO.

[46] UNESCO (2018). Global education meeting 2018: Brussels declaration. Paris: UNESCO.
[47] UNESCO GMR. (2015). Education for all 2000-2015. Paris: UNESCO.

[48] UNESCO (2005). Guidelines for inclusion: ensuring access to education for all. Paris.

[49] UNESCO (2019). Promoting inclusive teacher education materials. Paris: UNESCO.

[50] UNESCO (2016). Zambia education policy review: Paving the way for sdg 4 - education 2030.Paris: UNESCO.

[51] UNESCO-IBE (2016). Training tools for curriculum development - reaching out to all learners: a Resource Pack for supporting inclusive education.Geneva: International Bureau ofEducationUNESCO (IBE-UNESCO).

[52] UNICEF (2013). State of the world's children report. New York: UNICEF.

[53] Uited Nations (1989, November 20). Convention on the rights of the child. Retrieved March 29, 2020, from United Nations Human Rights: https://www.ohchr.org/en/professionalinterest/pages/crc.aspx

[54] United Nations (2016). Leaving no one behind: the imperative of inclusive development. New York: United Nations.

[55] United Nations (2019, May 8). Special edition: Progress towards the sustainable development goals. Retrieved April 1, 2020, from United Nations Economic and Social Council: https://undocs.org/E/2019/68

[56] United Nations (2016). Toolkit on disability for Africa: Disabilityinclusive development. Washington, D.C: : Department of Economic and Social Affairs.

[57] United Nations (2006). United nations convention on the rights of persons with disabilities. New York: UN.

[58] World Bank. (2018, November 30). Disability-inclusive education in Africa program. Retrieved April 12, 2020, from The World Bank:

https://www.worldbank.org/en/topic/disability/brief/disabilityinclusive-education-in-africa program

[59] Yin, R. (2003). Case study research: Design and methods (3rd ed.). Thousand Oaks, CA: Sage.

[60] Zambia National Educational Coalition (2018). Status of education in Zambia: Focus on inclusiveness of learners with special education needs. Lusaka: ZANEC.

[61] Zwane, S., \& Malale, M. (2018). Investigating barriers teachers face in the implementation of inclusive education in high schools in Gege branch, Swaziland. African Journal of Disability, 7. 